\title{
Irbesartan was renoprotective in patients with type 2 diabetes, hypertension, and microalbuminuria
}

\author{
Parving H-H, Lehnert H, Bröchner-Mortensen J, et al, for the Irbesartan in Patients with Type 2 Diabetes and \\ Microalbuminuria Study Group. The effect of irbesartan on the development of diabetic nephropathy in patients with type \\ 2 diabetes. $N$ Engl J Med 2001 Sep 20;345:870-8.
QUESTION: In patients with type 2 diabetes mellitus, hypertension, and persistent microalbuminuria, what is the effectiveness of the angiotensin II receptor antagonist (ARA) irbesartan for delaying or preventing the development of nephropathy?

Design

Randomised \{allocation concealed*\}†, blinded \{clinicians, patients, and outcome assessors $\}+*$, placebo controlled trial with 2 years of follow up.

\section{Setting}

96 centres worldwide.

\section{Patients}

611 patients between 30 and 70 years of age who had type 2 diabetes; hypertension defined as systolic blood pressure $>135 \mathrm{~mm} \mathrm{Hg}$ or diastolic blood pressure $>85 \mathrm{mg}$, or both; persistent microalbuminuria defined as an albumin excretion rate of 20 to $200 \mu \mathrm{g} /$ minute; and a serum creatinine concentration $\leqslant 133 \mu \mathrm{mol} / \mathrm{l}$ for men or $\leqslant 97 \mu \mathrm{mol} / \mathrm{l}$ for women. Exclusion criteria were non-diabetic kidney disease, cancer, fatal disease, or inhibitors or ARAs. 590 of $611(97 \%)$ patients (mean age $58 \mathrm{y}, 68 \%$ men) completed follow up.

Sources of funding:

Sanofi-Synthelabo and

Bristol-Myers Squibb.

For correspondence: Dr H Parving, Steno Diabetes Center,

Gentofte, Denmark.

hhp@novo.dk.

\section{Intervention}

Patients were allocated to receive irbesartan, 150 $\mathrm{mg} /$ day $(\mathrm{n}=195)$ or $300 \mathrm{mg} /$ day $(\mathrm{n}=194)$, or placebo $(\mathrm{n}=201)$. Patients were treated with antihypertensive indication for angiotensin converting enzyme (ACE)

drugs as needed, but ACE inhibitors were not allowed. Patients continued their usual diabetes care. Dietary salt and protein were not restricted.

\section{Main outcome measure}

Development of nephropathy, defined by a urinary albumin excretion rate $>200 \mu \mathrm{g} /$ minute that is at least $30 \%$ higher than the baseline rate.

\section{Main results}

Analysis was by intention to treat. At 2 years, unadjusted analyses showed that placebo was associated with a higher incidence of progression to nephropathy than was irbesartan, $300 \mathrm{mg} /$ day $(\mathrm{p}<0.001)$, but not irbesartan, $150 \mathrm{mg} /$ day ( $\mathrm{p}=0.08$ ). After adjusting for baseline microalbuminuria and blood pressure during the study, placebo was associated with a higher incidence of progression to nephropathy than was irbesartan, $300 \mathrm{mg} /$ day $(\mathrm{p}<0.001)$, and irbesartan, 150 $\mathrm{mg} /$ day $(\mathrm{p}=0.05)$ (table).

Irbesartan $v$ placebo for progression to nephropathy in type 2 diabetes, hypertension, and persistent microalbuminuria at 2 years

\begin{tabular}{lllll} 
Irbesartan dose & Irbesartan & Placebo & $\begin{array}{l}\text { Adjusted hazard ratio } \\
(95 \% \mathrm{Cl})\end{array}$ & NNT (Cl) \\
$150 \mathrm{mg} /$ day & $9.7 \%$ & $14.9 \%$ & $0.56(0.31$ to 0.99$)$ & $16(10$ to 728$)$ \\
\hline $300 \mathrm{mg} /$ day & $5.2 \%$ & $14.9 \%$ & $0.32(0.15$ to 0.65$)$ & 11 (8 to 21$)$ \\
\hline ¥Abbreviations defined in glossary; NNT and its $\mathrm{Cl}$ calculated by using hazard ratios provided in the article; haz-
\end{tabular}

\section{Conclusion}

In patients with type 2 diabetes mellitus, hypertension, and persistent microalbuminuria, irbesartan delayed progression to nephropathy independent of its effect on blood pressure.

*See glossary.
†Information provided by author.

\section{COMMENTARY}

Type 2 diabetes mellitus causes microvascular and macrovascular complications that pose public health concerns worldwide. The end organ damage resulting from microvascular complications clinically manifests itself as retinopathy, neuropathy, and nephropathy. Diabetic nephropathy causes almost $40 \%$ of all incident dialysis cases in the USA. Once end stage renal disease (ESRD) has developed, the median survival of patients with type 2 diabetes is 2 years, and most of these deaths are from cardiovascular disease.

In the spectrum of renal disease complicating diabetes, microalbuminuria precedes overt diabetic nephropathy. This stage is readily detectable, is associated with an increased risk for progression to diabetic nephropathy, and is potentially reversible.

Parving et al have shown that treating patients who have type 2 diabetes, hypertension, and microalbuminuria with irbesartan, $300 \mathrm{mg} / \mathrm{day}$, reduced progression to overt nephropathy at 2 years; lower doses $(150 \mathrm{mg} / \mathrm{d})$ were less effective. This beneficial effect of irbesartan was independent of blood pressure lowering and glycaemic control. In addition, irbesartan was more likely than placebo to cause regression to normoalbuminuria. The findings support the role of rennin-angiotensin system blockade with irbesartan in preventing progression to albuminuria.

The Microvascular Heart Outcomes Prevention Evaluation (MICRO-HOPE) study ${ }^{2}$ enrolled 3577 patients with diabetes, 32\% of whom had microalbuminuria. The rate of progression to overt nephropathy was lower in the ramipril group than in the placebo group (relative risk reduction [RRR] 24\%). Although the effects of irbesartan (RRR 66\%) seemed to be greater in preventing progression to overt nephropathy, no study exists with clinically important outcomes comparing ARAs to ACE inhibitors. 


\title{
Irbesartan reduced progression of nephropathy caused by type 2 diabetes independent of the effect on blood pressure
}

\author{
Lewis EJ, Hunsicker LG, Clarke WR, et al, for the Collaborative Study Group. Renoprotective effect of the \\ angiotensin-receptor antagonist irbesartan in patients with nephropathy due to type 2 diabetes. N Engl J Med 2001 \\ Sep 20;345:851-60. \\ QUESTION: In patients with type 2 diabetes mellitus, diabetic nephropathy, and \\ hypertension, what effect does the angiotensin II receptor antagonist (ARA) irbesartan \\ and the calcium channel blocker amlodipine have on renal disease?
}

\section{Design}

Randomised (allocation concealed*), blinded (clinicians, patients, outcome assessors, and statisticians),* placebo controlled trial with mean follow up of 2.6 years (the Irbesartan Diabetic Nephropathy Trial [IDNT]).

\section{Setting}

210 clinical centres worldwide.

\section{Patients}

1715 patients between 30 and 70 years of age (mean age 59 y, $66 \%$ men) who had type 2 diabetes, hypertension, proteinuria defined as a urinary protein excretion rate $\geqslant 900 \mathrm{mg} / 24$ hours, and serum creatinine concentrations between 88 and $265 \mu \mathrm{mol} / \mathrm{l}$ in women and between 106 and $265 \mu \mathrm{mol} / \mathrm{l}$ in men. Follow up was $99 \%$.

\section{Intervention}

Patients were allocated to irbesartan, titrated to 300 $\mathrm{mg}$ /day ( $\mathrm{n}=579$ ); amlodipine, titrated to $10 \mathrm{mg} /$ day $(\mathrm{n}=567)$; or placebo $(\mathrm{n}=569)$. Treatment targeted a systolic blood pressure $\leqslant 135 \mathrm{~mm} \mathrm{Hg}$ and a diastolic blood pressure $\leqslant 85 \mathrm{~mm} \mathrm{Hg}$ by using drugs other than angiotensin converting enzyme (ACE) inhibitors, angiotensin receptor blockers, and calcium channel blockers, if necessary.

\section{Main outcome measures}

The primary outcome was the composite of a doubling of the baseline serum creatinine concentration, onset of end stage renal disease, or all cause mortality. The secondary outcome was the composite of cardiovascular mortality, non-fatal myocardial infarction, heart failure resulting in admission to hospital, neurological deficit caused by a cerebrovascular event, or above ankle lower limb amputation.

\section{Main results}

Analysis was by intention to treat. After adjusting for mean blood pressure, irbesartan lowered the risk for the primary composite outcome more than did amlodipine $(\mathrm{p}=0.005)$ or placebo $(\mathrm{p}=0.03)$; this outcome did not differ for amlodipine and placebo $(\mathrm{p}=0.47)$ (table). The 3 groups did not differ for the secondary composite outcome.

\section{Conclusion}

In patients with type 2 diabetes, nephropathy, and hypertension, irbesartan was more effective in reducing progression of nephropathy independent of the effect on blood pressure than was amlodipine or placebo.

*See glossary.

Irbesartan, amlodipine, or placebo for risk for a composite outcome in diabetic nephropathy and hypertension at mean 2.6 years ${ }^{\dagger}$

\begin{tabular}{llll} 
Comparisons & Event rates & Adjusted RRR (95\% CI) & NNT (CI) \\
Irbesartan $v$ amlodipine & $33 \% v 41 \%$ & $24 \%(8$ to 37$)$ & 12 (7 to 35$)$ \\
\hline Irbesartan $v$ placebo & $33 \% v 39 \%$ & $19 \%(1$ to 33$)$ & 16 (8 to 121$)$ \\
& & Adjusted RRI (CI) & NNH \\
Amlodipine $v$ placebo & $41 \% v 39 \%$ & $7 \%(-11$ to 29$)$ & Not significant
\end{tabular}

†Composite outcome $=$ doubling of baseline serum creatinine level, end stage renal disease, or all cause mortality. Abbreviations defined in glossary; RRR, RRI, and $\mathrm{Cl}$ adjusted for mean arterial blood pressure; NNT, NNH, and $\mathrm{Cl}$ calculated from data in article.

\section{COMMENTARY — continued from previous page}

The study of Mogensen $e t \mathrm{al}^{3}$ provides a preliminary assessment of the role of combination treatment with ARAs and ACE inhibitors in the candesartan and lisinopril microalbuminuria (CALM) study. Candesartan combined with lisinopril for 24 weeks resulted in greater reductions in blood pressure and in the albumin : creatinine ratio than either drug given alone.

Once overt nephropathy develops, the goal of treatment is to slow the rate of progression to ESRD. The IDNT and the RENAAL trials, which used irbesartan and losartan, respectively, showed that patients treated with ARAs had a lower incidence of the composite outcome of doubling of serum creatinine, ESRD, or death. The effect of amlodipine on progression to the composite end point was neutral. After the baseline visit, mean systolic blood pressure levels ranged from $140 \mathrm{~mm}$ to $150 \mathrm{~mm} \mathrm{Hg}$, and diastolic blood pressure levels ranged from $74 \mathrm{~mm}$ to $77 \mathrm{~mm} \mathrm{Hg}$. A mean of 3 to 4 additional non-study medications were needed to achieve these blood pressure levels. Mean proteinuria concentrations decreased by $33 \%$ to $35 \%$ in the ARA treated groups. These trials provide convincing evidence that irbesartan and losartan reduce the risk for progression of renal disease.

Preventing progression of diabetic nephropathy should not be considered in isolation from macrovascular complications associated with type 2 diabetes. In middle aged and elderly people with type 2 diabetes, fatal and non-fatal cardiovascular events occur at a rate of $4 \%$ to $5 \%$ per year. The HOPE study ${ }^{4}$ strongly supports a protective effect of ramipril (RRR 22\%) on future cardiovascular events in high risk patients, including those with diabetes and $\geqslant 1$ additional cardiovascular risk factor. Although the HOPE trial excluded patients with overt proteinuria, patients with proteinuria and type 2 diabetes would probably have a similar benefit.

Both the IDNT and RENAAL studies used prespecified secondary outcome clusters to measure morbidity and mortality from cardiovascular causes. Secondary outcomes occurred in $24 \%$ of patients in the IDNT study and $34 \%$ of patients in the RENAAL study. Neither losartan nor irbesartan reduced the risk for this composite outcome; however, losartan was associated with a lower rate of first admission to hospital for congestive heart failure. 


\title{
Losartan was renoprotective in diabetic nephropathy independent of its effect on blood pressure
}

\author{
Brenner BM, Cooper ME, de Zeeuw D, et al, for the RENAAL Study Investigators. Effects of losartan on renal and \\ cardiovascular outcomes in patients with type 2 diabetes and nephropathy. N Engl J Med 2001 Sep 20;345:861-9. \\ QUESTION: In patients with type 2 diabetes mellitus and nephropathy, what is the \\ renoprotective effect of the angiotensin II receptor antagonist (ARA) losartan?
}

\begin{abstract}
Design
Randomised (allocation concealed*), blinded (clinicians, patients, outcome assessors, and statisticians),* placebo controlled trial with mean follow up of 3.4 years (the Reduction of Endpoints in NIDDM with the Angiotensin II Antagonist Losartan [RENAAL] Study).
\end{abstract}

Setting

250 centres worldwide.

\section{Patients}

1513 patients between 31 and 70 years of age (mean age 60 y, 63\% men) who had type 2 diabetes and nephropathy defined as a urinary albumin : creatinine ratio $\geqslant 300$ $\mathrm{mg} / \mathrm{g}$ and a serum creatinine concentration between 115 and $265 \mu \mathrm{mol} / \mathrm{l}(\geqslant 133 \mu \mathrm{mol} / \mathrm{l}$ for men weighing $>60 \mathrm{~kg}$ ). Exclusion criteria included type 1 diabetes and non-diabetic renal disease. Follow up was $99.8 \%$.

Source of funding:

Merck and Company.

For correspondence: $\mathrm{Dr}$ B M Brenner, Brigham and Women's Hospital, Boston, MA, USA.

bbrenner@partners.org.

\section{Intervention}

After stratification by baseline level of proteinuria, patients were allocated to receive losartan, 50 to 100 $\mathrm{mg} /$ day $(\mathrm{n}=751)$, or placebo $(\mathrm{n}=762)$. Conventional antihypertensive treatment (excluding angiotensin I con- verting enzyme inhibitors and ARAs) was adjusted to target a systolic and diastolic blood pressure $<140$ and $<90 \mathrm{~mm} \mathrm{Hg}$, respectively.

\section{Main outcome measures}

The primary outcome was the composite of a doubling of the baseline serum creatinine concentration, end stage renal disease (ESRD), or death. The secondary outcome was the composite of cardiovascular morbidity or mortality.

\section{Main results}

Analysis was by intention to treat. Losartan reduced the risk for the primary composite outcome (unadjusted $\mathrm{p}=0.02 ; \mathrm{p}=0.03$ after adjustment for blood pressure), doubling of the baseline serum creatinine concentration (unadjusted $\mathrm{p}=0.006$ ), and ESRD (unadjusted $\mathrm{p}=0.002$ ) more than did placebo (table). However, losartan and placebo did not differ for incidence of death (unadjusted $\mathrm{p}=0.88$ ) (table) or the secondary composite outcome of cardiovascular morbidity or mortality $(\mathrm{p}=0.26)$.

Losartan $v$ placebo for type 2 diabetes and nephropathy at 3.4 years $\dagger$

\begin{tabular}{|c|c|c|c|}
\hline Outcomes & Losartan & Placebo & RRR $(95 \% \mathrm{Cl}) \ddagger$ \\
\hline Composite outcome§ & $44 \%$ & $47 \%$ & $16 \%(2$ to 28$)$ \\
\hline Doubling of serum creatinine level & $22 \%$ & $26 \%$ & $25 \%$ (8 to 39$)$ \\
\hline End-stage renal disease & $20 \%$ & $26 \%$ & $28 \%$ (11 to 42$)$ \\
\hline
\end{tabular}

line serum creatinine level, end-stage renal disease, or death.

COMMENTARY — continued from previous page

Patients and their clinicians must now consider using these 2 classes of drugs. Treatment for individual patients should consider the risk for progression of renal disease, risk for future cardiovascular events, and blood pressure.

The treatment of type 2 diabetes should start early in the course of the disease process. At the normoalbuminuric or microalbuminuric stage, ACE inhibitors should be considered first line agents because of their proven efficacy in preventing progression to overt nephropathy and reducing cardiovascular events. Attention should also focus on blood pressure control and modification of other risk factors for cardiovascular disease.

Once nephropathy has developed, the importance of rennin-angiotensin system blockade persists, but the choice of drug is less clear. Clinicians should expect to use 3 to 4 different drugs to achieve a good blood pressure reading. Although further research using clinically important outcomes is required, dual blockade of the rennin-angiotensin system with a combined ACE inhibitor and ARA seems promising. This combination may offer the best of both treatment strategies and result in lower incidence rates of devastating microvascular and macrovascular complications in people with type 2 diabetes.

Christian G Rabbat, MD McMaster University Hamilton, Ontario, Canada

1 United States renal data system. USRDS 2000 annual data report. 2000. Bethesda: National Institutes of Health, 2000. http://www.usrds.org/adr_2000.htm.

2 The Heart Outcomes Prevention Evaluation Study Investigators. Effects of ramipril on cardiovascular and microvascular outcomes in people with diabetes mellitus: results of the HOPE study and MICRO-HOPE substudy. Lancet 2000;355:253-9.

3 Mogensen CE, Neldam S, Tikkanen I, et al. Randomised controlled trial of dual blockade of rennin-angiotensin system in patients with hypertension, microalbuminuria, and non-insulin dependent diabetes: the candesartan and lisinopril microalbuminuria (CALM) study. BMJ 2000;321:1440-4.

4 The Heart Outcomes Prevention Evaluation Study Investigators. Effects of an angiotensin-converting enzyme inhibitor, ramipril, on cardiovascular events in highrisk patients. N Engl J Med 2000;342:145-53. 